\title{
Continuous Fetal Monitoring During Electroconvulsive Therapy: A Prospective Observation Study
}

This article was published in the following Dove Press journal: International Journal of Women's Health

\author{
Nader Rabie ${ }^{\prime}$ \\ Ronak Shah ${ }^{2}$ \\ Shona Ray-Griffith ${ }^{3}$ \\ Jessica L Coker ${ }^{3}$ \\ Everett F Magann (D) ${ }^{4}$ \\ Zachary N Stowe ${ }^{5}$ \\ 'Tripler Army Medical Center, \\ Department of Obstetrics and \\ Gynecology, Honolulu, HI, USA; ${ }^{2}$ Our \\ Lady of Angels, Department of \\ Obstetrics and Gynecology, Bogalusa, LA, \\ USA; ${ }^{3}$ University of Arkansas for Medical \\ Sciences, Department of Psychiatry, Little \\ Rock, AR, USA; ${ }^{4}$ University of Arkansas \\ for Medical Sciences, Department of \\ Obstetrics and Gynecology, Little Rock, \\ AR, USA; ${ }^{5}$ University of Wisconsin \\ School of Medicine and Public Health, \\ Psychiatric Institute and Clinic, Madison, \\ WI, USA
}

Objective: The use of electroconvulsive therapy in pregnancy has been limited by concerns about its effects on fetal well-being, despite limited evidence that suggests it is safe and effective. No studies have utilized continuous fetal heart rate monitoring during electroconvulsive therapy sessions. We aimed to describe the fetal heart rate patterns of patients undergoing electroconvulsive therapy.

Design: This study is a prospective case series of pregnant patients undergoing electroconvulsive therapy with continuous fetal heart rate monitoring.

Setting: University-based hospital.

Population: Pregnant patients with a psychiatric indication for electroconvulsive therapy. Methods: Patients underwent fetal heart rate monitoring immediately prior, during and immediately after ECT therapy.

Main Outcome Measures: Characterization of the fetal heart rate tracing.

Results: Five subjects underwent 44 electroconvulsive therapy sessions. Continuous fetal monitoring was performed on 34 of the sessions. Transient fetal heart rate decelerations occurred in 4 sessions, all self-resolved and none required intervention.

Conclusion: This case series is the first to report the results of continuous FHR monitoring during electroconvulsive therapy. The most common finding was a transient, self-resolving bradycardia that was not associated with adverse perinatal outcomes. This supports the opinion that electroconvulsive therapy is a safe treatment option in pregnancy in women with severe mental disease.

Keywords: pregnancy, electroconvulsive therapy, fetal monitoring, mental illness and pregnancy

\section{Introduction}

Mental illness affects $11-20 \%$ of pregnant women and is a risk factor for adverse perinatal outcomes including preterm birth. ${ }^{1,2}$ Diagnosing and treating mental illness is challenging because many of the symptoms mimic normal pregnancy symptoms and there is a gap between Obstetrician's comfort treating mental health disorders and Psychiatrists' comfort treating pregnant patients. Current treatments include pharmacotherapy, psychotherapy, and electroconvulsive therapy (ECT). ${ }^{3}$ Pharmacotherapy is the most frequent treatment even though it is the only one with a potential teratogenic risk and risk of neonatal irritability. ${ }^{4,5}$ Conversely, ECT has no teratogenic risk, greater efficacy rates for the majority of mental illnesses but is underutilized because of a fear of fetal harm. The American Congress of
Correspondence: Everett F Magann University of Arkansas for Medical Sciences, Department of Obstetrics and Gynecology, Little Rock, AR, USA Email efmagann@uams.edu
International Journal of Women's Health 2021:13 1-7

(c) (i) (5) 2021 Rabie et al. This work is published and licensed by Dove Medical Press Limited. The full terms of this license are available at https://www.dovepress.com/terms.php C. $\mathrm{BY}_{\mathrm{NC}}$ and incorporate the Creative Commons Attribution - Non Commercial (unported, v3.0) License (http://creativecommons.org/licenses/by-nc/3.0/). By accessing the work you hereby accept the Terms. Non-commercial uses of the work are permitted without any further permission from Dove Medical Press Limited, provided the work is properly attributed. For permission for commercial use of this work, please see paragraphs 4.2 and 5 of our Terms (https://www.dovepress.com/terms.php). 
Obstetricians and Gynecologists (ACOG) and the American Psychiatric Association (APA) endorse ECT use in pregnancy citing minimal evidence of maternal or fetal harm. ${ }^{5}$

ECT was first used clinically in 1935 and was commonly used through the 1980s. After a decline in use secondary to its negative portrayal in the media, ${ }^{6}$ it has started to regain popularity. ${ }^{7}$ The exact mechanism of action is unknown, but response rates for depression and mania are as high as $87 \% .^{8-11}$ High efficacy rates and a favorable risk: benefit ratio make ECT an attractive option for perinatal mood disorders.

Information on ECT use in pregnancy is limited to case reports and case series. Several studies discuss precautions to take in pregnant patients, but there are no consistent guidelines for the performance of ECT in pregnancy. ${ }^{12-14}$ These precautions include left lateral decubitus positioning, IV hydration, use of proton pump inhibitors or $\mathrm{H} 2$ blockers, and intubation. Other precautions include performance of a pelvic exam, avoidance of hyperventilation, and some form of fetal monitoring. ${ }^{12-14}$

There is no consistent guideline for fetal monitoring during ECT and no consistent patterns of adverse outcomes. $^{13}$ The timing (pre/post ECT) and duration of fetal monitoring are not well described. In general, auscultation of the FHR is accepted pre and post procedure when prior to 24 weeks gestation; while after 24 weeks gestation it is typical to obtain a non-stress test pre and post procedure. A large literature review in 2013 discussed various adverse outcomes including fetal decelerations, uterine contractions, preterm labor, and fetal/neonatal loss. $^{15}$ However, consistent with current studies, this review consisted of case reports and case series. In addition, 2/3 of the patients were from studies prior to 1970 . The most common adverse event in this review was FHR decelerations, but the specifics of these FHR decelerations are not available. In addition, the nature of fetal monitoring was inconsistent. ${ }^{15}$ There is a need for more current information on FHR patterns during ECT. To our knowledge, there is no data regarding continuous fetal heart rate (FHR) monitoring during the actual ECT procedure. The purpose of this investigation was to evaluate continuous FHR monitoring on pregnant patients undergoing ECT and determine the effects of ECT on the FHR pattern.

\section{Methods}

This is a prospective, observational study approved by the Institutional Review Board of the University of Arkansas for
Medical Sciences (UAMS) (IRB 203244), and was conducted in accordance with the Declaration of Helsinki. Informed consent was obtained from all subjects prior to any study procedures. All subjects were deemed competent to make healthcare decisions. Subjects were recruited from November 2014 through December 2015. Potential subjects were identified through the Women's Mental Health Division of the UAMS Psychiatric Research Institute after an evaluation and discussion of the risk and benefits of each available treatment. Patients previously on medical therapy were offered ECT when they failed medical management. Otherwise, patients were offered ECT when they had new onset major depression, bipolar disorder, or suicidal ideation requiring inpatient management. All pregnant patients who were offered and agreed to ECT therapy as part of their treatment plan were invited to participate. As part of the study, demographic, medical, psychiatric, and obstetric histories were obtained from the patient and the electronic medical record. The primary outcome was characterization of the fetal heart rate during ECT. Secondary outcomes included any adverse perinatal outcomes from the time of ECT through delivery.

The current UAMS policy for FHR monitoring during ECT is dependent on estimated gestational age (EGA). For pregnancies $<24$ weeks EGA, the FHR is documented prior to and following the ECT. For pregnancies $\geq 24$ weeks EGA, a nonstress test (NST) is obtained prior to and following the procedure. In addition, the ECT suite is located relatively close to Labor and Delivery (L\&D) and the L\&D providers are notified when a pregnant patient is undergoing ECT. This allows rapid transport of a patient to L\&D in the case of an adverse event.

In our study, we expanded FHR monitoring from pre/ post to continuous monitoring prior to, during, and following the procedure regardless of gestational age with either a handheld Doppler or using an electronic FHR monitor (GE Corometrics 250cx, Wisconsin, USA). Fetal monitoring was initiated once a patient was moved from the preparation area into the ECT suite. The monitor was held in place during preparation, anesthesia induction, ECT initiation and completion, and for 10 minutes following extubation. In addition, if the patient's gestational age was $>24$ weeks, an NST was obtained after the patient was moved to the recovery area. Data on ECT parameters and birth information was collected on each patient.

The ECT was performed in the UAMS Psychiatric Research Institute ECT suite using a Mecta Spectrum 5000Q device (Tualatin, Oregon). This ECT was an ultra- 
brief ECT. Pulse wave current (800 mA) was utilized with right unilateral electrode placement. Patients were monitored with electroencephalography (EEG) during and after the stimulation and the seizure activity was confirmed centrally using EEG and peripherally by observing the patient. A maximum of three treatments were administered each week, typically on Monday, Wednesday, and Friday. Per standard of care, patients $>16$ weeks EGA were intubated during the treatment. The choice of anesthetic and muscle relaxant was left to the discretion of the anesthesia provider. Subjects 1 and 2 received ketamine and propofol. Subject 3 received methohexital and propofol, except for sessions 4 and 5, during which she received ketamine and succinylcholine. Subjects 4 and 5 received methohexital and propofol.

\section{Results}

During the study period, seven subjects were offered ECT and were enrolled in the study. However, two patients subsequently decided to pursue pharmacotherapy and were removed from the study. The remaining five patients underwent a total of 44 ECT sessions. Table 1 lists each patient's ECT treatment characteristics. All the subjects were in good physical health. Subject \#1 had well-controlled hypothyroidism and a history of migraines, and subject \#3 was currently being treated for migraines. All the patients except for subject \#4 had ECT initiated as an inpatient.

Fetal heart rate monitoring was performed in 34/44 sessions. Subject \#3 did not have monitoring performed for the first 10 treatments because of her early gestational age. At 11 2/7 weeks of gestation (treatment 11), it was possible to detect the FHR with the handheld Doppler and monitoring was initiated at that point. In addition, FHR paper tracings were not available for review on the last 2 sessions for subject \#3. Of the remaining 32 sessions, every FHR tracing was reassuring before and during the ECT procedure.
After 4 of the sessions, post-procedure decelerations were observed. The decelerations occurred as follows: (1) at $182 / 7$ weeks, subject 1 had a fetal deceleration that lasted 1 minute following a seizure of 95 seconds duration, (2) at 18 2/7 weeks, subject 2 had a fetal deceleration that lasted 3 minutes following a seizure of 180 seconds duration, (3) at 18 2/7 weeks, subject 3 had a fetal deceleration lasting 2 minutes following a seizure of 89 seconds duration, and (4) at 30 0/7 weeks, subject 4 had a fetal deceleration lasting 4 minutes following a seizure of 199 seconds duration. All decelerations were defined as a drop from baseline $>30 \mathrm{bpm}$ and none had a nadir below $90 \mathrm{bpm}$. Of note, it is purely coincidental that three of the decelerations occurred at 18 2/7 weeks gestation. None of the patients underwent prolonged monitoring, further antenatal assessments, or an emergent delivery for a non-reassuring FHR.

There were no complications with any of the ECT treatments. All of the patients reported improvement in their symptoms after their prescribed course of therapy; although subject \#4 had limited improvement and subject \#5 was readmitted to the psychiatry service due to relapse of her depression. On readmission, she was managed with medication and declined additional ECT treatments.

The subjects reported a variety of the known side effects of ECT that included muscle soreness, headaches, memory loss, nausea, and fatigue. All of these symptoms were managed conservatively or with commonly used medications (eg, acetaminophen for headache). No patients reported vaginal bleeding. There were intermittent complaints of preterm contractions, but none of these contractions became regular or led the patient to undergo additional monitoring or be moved to labor and delivery. Subject \#5 reported chest pain and shortness of breath after her 2 nd treatment. Her evaluation was negative and her symptoms self-resolved. Of note during her admission,

Table I Descriptive Characteristics of Patients and ECT Sessions

\begin{tabular}{|c|c|c|c|c|c|c|c|}
\hline Subjects & Age & Diagnosis & \#ECT & $\begin{array}{l}\text { EGA Span of } \\
\text { ECT }\end{array}$ & Medications & $\begin{array}{l}\text { Central Seizure } \\
\text { Duration }\end{array}$ & $\begin{array}{l}\text { Peripheral } \\
\text { Seizure Duration }\end{array}$ \\
\hline 1 & 25 & Depression Anxiety & 2 & $180 / 7-182 / 7$ & Clonazepam Lamotrigine & $43-56 \mathrm{sec}$ & $35-39 \mathrm{sec}$ \\
\hline 2 & 24 & Bipolar disorder & 9 & $166 / 7-241 / 7$ & $\begin{array}{l}\text { Nortriptyline Lithium } \\
\text { Promethazine Opiates }\end{array}$ & $44-137 \mathrm{sec}$ & $44-112 \mathrm{sec}$ \\
\hline 3 & 35 & $\begin{array}{l}\text { Bipolar disorder Depression } \\
\text { Anxiety Suicidal ideation }\end{array}$ & 23 & $300 / 7-312 / 7$ & $\begin{array}{l}\text { Fluoxetine Buspirone } \\
\text { Nortriptyline }\end{array}$ & $30-106 \mathrm{sec}$ & $25-56 \mathrm{sec}$ \\
\hline 4 & 29 & Depression Social anxiety & 6 & $300 / 7-316 / 7$ & Sertraline Buspirone Haldol & $114-133 \mathrm{sec}$ & $50-74 \mathrm{sec}$ \\
\hline 5 & 22 & Depression Suicidal ideation & 4 & $346 / 7-362 / 7$ & None & $39-62 \mathrm{sec}$ & $39-50 \mathrm{sec}$ \\
\hline
\end{tabular}


she had multiple somatic complaints, none of which led to an adverse maternal or perinatal outcome.

All five subjects had uncomplicated term deliveries. Four infants had an uncomplicated neonatal hospital course. Subject \# 3 transferred her care near the end of her pregnancy and only the delivery information was available.

\section{Discussion}

Our study adds to the limited existing data that selfresolving fetal bradycardia is the most common adverse effect. To our knowledge, this series of 34 ECT procedures is the first study examining continuous FHR monitoring while undergoing ECT treatment. ${ }^{12,15,16}$ Isolated fetal decelerations were observed after 4 of the 32 cases for which results were available. Each deceleration selfresolved within 4 minutes and there were no negative fetal outcomes. Three of the 4 decelerations occurred at 18 weeks' gestation, which is a time in pregnancy when continuous FHR monitoring is not performed. Therefore, the prevalence of FHR decelerations at this gestational age is unknown. In addition, isolated fetal decelerations are common and generally of no significance when followed by an otherwise reassuring FHR. The standard method of fetal monitoring in ECT remains unknown; however, our preliminary study indicates that continuous FHR monitoring is of no additional benefit.

In our study, there were ECT sessions in which the central seizure duration was significantly longer than the peripheral seizure duration. We could not identify any studies describing a standard relationship between these two durations, nor the effect of pregnancy on seizure duration in the setting of ECT. While it is possible that pregnancy may effect seizure duration, there was no correlation between the length of seizures and the ECT sessions with the fetal decelerations.

In addition, our case series augments other studies supporting the utilization of ECT during pregnancy and suggests that ECT poses minimal risk to both the patient and fetus. Prior studies would suggest that adverse outcomes, such as preterm delivery and fetal loss (both miscarriage and stillbirth), are significantly higher in patients undergoing ECT. ${ }^{15}$ Unfortunately, the time interval between ECT and delivery is not listed in many of the studies. We do know preterm contractions have been reported many times after ECT; ${ }^{17-23}$ however, the majority of cases self-resolve. The electrical component of ECT only affects skeletal muscle; therefore, the uterus is unaffected by the therapy. In addition, the at-risk population undergoing ECT often suffers from several risk factors for preterm delivery including mental health disorders, substance abuse, and low socioeconomic status. Studies also differ on intubation for the ECT. Our institutional policy by anesthesia is to intubate after 16 weeks but not all expert agree with intubation because of concerns about the increased vascularity and airway edema of pregnancy. ${ }^{24}$ These significant confounding factors should also be considered.

Of the eleven fetal losses reported in the literature, only one appears related to ECT. This was a stillbirth following ECT induced status epilepticus. ${ }^{25}$ The remaining losses do not appear related to ECT, either because of the timing of the demise (weeks to months following ECT) or the specific cause of death (eg, anencephaly, bronchopneumonia, lung cysts, and meconium peritonitis). ${ }^{26-32}$ This previous study also shows a $20 \%$ fetal anomaly rate, which is much higher than the general population rate of $3 \%{ }^{15,33}$ However, these cases either had fetal anomalies detected prior to the initiation of ECT or the ECT was performed in the 2nd and 3rd trimesters, after organogenesis was complete. ${ }^{15,16}$

Strengths of our study include the relatively large number of monitored ECT sessions and the wide range of gestational ages included in the study. There are also limitations of our study. One is the small number of patients and lack of a control group. However, given the relatively infrequent use of ECT and the special ethical considerations of pregnancy, it is questionable whether a well-powered randomized controlled trial (RCT) will ever be performed. We did not perform simultaneous tocodynamometry during the ECT, as we were only interested in the fetal heart rate. However, it is unusual in an Obstetric population to monitor the FHR without simultaneously monitoring uterine contractions. Another limitation in examining the safety of ECT is publication bias. With no RCTs, the majority of data on this controversial treatment modality will come from case reports, case series, systematic reviews and similar. We must also consider that a significant number of cases will not be reported because they were uneventful and of no academic interest. Our recent review examined the available data on ECT in pregnancy and concluded that it is a safe and effective therapy in the appropriate setting with recommendations for administering ECT in pregnancy $^{12}$ (Table 2). 
Table 2 Recommendations for Performing ECT in Pregnant Patients

\begin{tabular}{|l|l|}
\hline $\begin{array}{l}\text { Fetal Heart Rate } \\
\text { Monitoring }\end{array}$ & \\
\hline $\begin{array}{l}<24 \text { weeks } \\
\geq 24 \text { weeks }\end{array}$ & $\begin{array}{l}\text { Fetal heart tones before and after procedure } \\
\text { Non stress test before and after procedure }\end{array}$ \\
\hline $\begin{array}{l}\text { Anesthesia } \\
\text { Premedication }\end{array}$ & $\begin{array}{l}\text { H2 blocker or proton pump inhibitor } \\
\text { IV hydration }\end{array}$ \\
\hline $\begin{array}{l}\text { Induction agents } \\
\text { Technique }\end{array}$ & $\begin{array}{l}\text { Recommend intubation } \\
\text { Methohexital or propofol } \\
\text { Avoid hyperventilation } \\
\text { Left lateral decubitus positioning with a wedge (>20 weeks) }\end{array}$ \\
\hline $\begin{array}{l}\text { Location } \\
<24 \text { weeks } \\
\geq 24 \text { weeks }\end{array}$ & $\begin{array}{l}\text { Any ECT facility } \\
\text { In proximity to labor and delivery facility }\end{array}$ \\
\hline $\begin{array}{l}\text { Medications } \\
\text { Pregnancy specific conditions }\end{array}$ & $\begin{array}{l}\text { Withhold antiepileptic medications the night before } \\
\text { Preeclampsia and placenta previa are not contraindications, but patients should be medically stable prior to } \\
\text { undergoing ECT }\end{array}$ \\
\hline
\end{tabular}

Notes: A This should be adjusted to the specific institution's gestational age for neonatal resuscitation; ${ }^{\mathrm{B}}$ If there is no obstetric facility near the ECT facility, patients should be counseled that the likelihood of needing emergent obstetric care is very low and it is safe to proceed with ECT.

\section{Conclusion}

Pharmacotherapy and psychotherapy will remain as the primary treatments for mild mental disorders, such as mild depression and anxiety in pregnancy. Although ECT is often reserved for acute suicidal ideation or severe refractory depression and bipolar disorder, our study supports ECT as a safe treatment option for mood disorders in the perinatal period. Furthermore, continuous FHR monitoring can be logistically challenging and labor intensive, and our study suggests that there is no additional benefit to continuous FHR monitoring. Additional studies could incorporate more patients and add to the available data of FHR monitoring during ECT.

\section{Details of Ethics Approval}

This study was approved by the Institutional Review Board of the University of Arkansas for Medical Sciences (UAMS) (IRB 203244), and was conducted in accordance with the Declaration of Helsinki.

\section{Acknowledgments}

The authors would like to acknowledge Donna Eastham for her assistance in proofreading and technical editing.

\section{Author Contributions}

All authors made a significant contribution to the work reported, whether that is in the conception, study design, execution, acquisition of data, analysis and interpretation, or in all these areas; took part in drafting, revising or critically reviewing the article; gave final approval of the version to be published; have agreed on the journal to which the article has been submitted; and agree to be accountable for all aspects of the work.

\section{Funding}

No funding was received for this work.

\section{Disclosure}

Shona Ray-Griffith reports grants from NIH, during the conduct of the study and receives support from the Translational Research Institute (TRI), grants UL1TR000039 and KL2TR000063 through the NIH National Center for Research Resources and the National Center for Advancing Translational Sciences; she currently receives clinical trial support from Sage Therapeutics and Neuronetics; she reports no directing funding source for this study and declares no conflict of interest. Jessica Coker reports grants from Brain and Behavior Research Foundation, National Institute on Drug Abuse, National Center for Advancing Translational Sciences, and Arkansas Children's Research Institute, outside the submitted work; reports no direct funding source for this study and declares no conflict of interest. Zachary Stowe reports grants from NIH and CDC, personal fees from Sage Therapeutics, and external promotion review committee for 
Harvard/Brigham, outside the submitted work; receives research support from, consults for and receives speakers' honoraria for GlaxoSmithKline, Pfizer and Wyeth Corporations; reports no direct funding for this project and declares no conflict of interest for this project. The authors report no other potential conflicts of interest for this work.

\section{References}

1. Gaynes BN, Gavin N, Meltzer-Brody S, et al. Perinatal depression: prevalence, screening accuracy, and screening outcomes. Evid Rep Technol Assess (Summ). 2005;119:1-8.

2. Scholle SH, Haskett RF, Hanusa BH, Pincus HA, Kupfer DJ. Addressing depression in obstetrics/gynecology practice. Gen Hosp Psychiatry. 2003;25(2):83-90. doi:10.1016/S0163-8343(03)00006-9

3. Yonkers KA, Wisner KL, Stewart DE, et al. The management of depression during pregnancy: a report from the American psychiatric association and the American college of obstetricians and gynecologists. Gen Hosp Psychiatry. 2009;31(5):403-413. doi:10.1016/j.genhosppsych.2009.04.003

4. Bulletins-Obstetrics ACoP. ACOG practice bulletin: clinical management guidelines for obstetrician-gynecologists number 92, April 2008 (replaces practice bulletin number 87, November 2007). Use of psychiatric medications during pregnancy and lactation. Obstet Gynecol. 2008;111(4):1001-1020. doi:10.1097/AOG.0b013e31816fd910

5. Yonkers KA, Wisner KL, Stewart DE, et al. The management of depression during pregnancy: a report from the American psychiatric association and the American college of obstetricians and gynecologists. Obstet Gynecol. 2009;114(3):703-713. doi:10.1097/ AOG.0b013e3181ba0632

6. Shorter E, Healy D. Shock Therapy: A History of Electroconvulsive Treatment in Mental Illness. New Brunswick, N.J.: Rutgers University Press; 2007.

7. Munk-Olsen T, Laursen TM, Videbech P, Rosenberg R, Mortensen PB. Electroconvulsive therapy: predictors and trends in utilization from 1976 to 2000. J ECT. 2006;22(2):127-132. doi:10.1097/00124509-200606000-00010

8. Petrides G, Fink M, Husain MM, et al. ECT remission rates in psychotic versus nonpsychotic depressed patients: a report from CORE. $J$ ECT. 2001;17(4):244-253. doi:10.1097/00124509-200112000-00003

9. Group UER. Efficacy and safety of electroconvulsive therapy in depressive disorders: a systematic review and meta-analysis. Lancet. 2003;361 (9360):799-808. doi:10.1016/S0140-6736(03)12705-5

10. Hiremani RM, Thirthalli J, Tharayil BS, Gangadhar BN. Doubleblind randomized controlled study comparing short-term efficacy of bifrontal and bitemporal electroconvulsive therapy in acute mania. Bipolar Disord. 2008;10(6):701-707. doi:10.1111/j.1399-5618.200 8.00608.x

11. Pompili M, Lester D, Dominici G, et al. Indications for electroconvulsive treatment in schizophrenia: a systematic review. Schizophr Res. 2013;146(1-3):1-9. doi:10.1016/j.schres.2013.02.005

12. Ray-Griffith SL, Coker JL, Rabie N, Eads LA, Golden KJ, Stowe ZN. Pregnancy and electroconvulsive therapy: a multidisciplinary approach. $J \quad E C T . \quad 2016 ; 32(2): 104-112$. doi:10.1097/YCT.0000000000000297

13. Miller LJ. Use of electroconvulsive therapy during pregnancy. Hosp Community Psychiatry. 1994;45(5):444-450.
14. Remick RA, Maurice WL. ECT in pregnancy. Am J Psychiatry. 1978;135(6):761-762. doi:10.1176/ajp.135.6.761-c

15. Leiknes KA, Cooke MJ, Jarosch-von Schweder L, Harboe I, Hoie B. Electroconvulsive therapy during pregnancy: a systematic review of case studies. Arch Womens Ment Health. 2013;18:1-39. doi:10.1007/s00737-0130389-0

16. Anderson EL, Reti IM. ECT in pregnancy: a review of the literature from 1941 to 2007. Psychosom Med. 2009;71(2):235-242. doi:10.1097/PSY.0b013e318190d7ca

17. Fukuchi T, Okada Y, Katayama H, et al. [A case of pregnant woman with severe obsessive-compulsive disorder successfully treated by modified-electroconvulsive therapy]. Seishin Shinkeigaku Zasshi = Psychiatria Et Neurologia Japonica. 2003;105(7):927-932.

18. Sherer DM, D'Amico ML, Warshal DP, Stern RA, Grunert HF, Abramowicz JS. Recurrent mild abruptio placentae occurring immediately after repeated electroconvulsive therapy in pregnancy. Am $J$ Obstet Gynecol. 1991;165(3):652-653. doi:10.1016/0002-9378(91)90302-8

19. Ishikawa T, Kawahara S, Saito T, et al. [Anesthesia for electroconvulsive therapy during pregnancy-a case report]. Masui JapanJ Anesthesiol. 2001;50(9):991-997.

20. Boyd DA, Brown DW. Electric convulsive therapy in mental disorders associated with childbearing. Mo Med. 1948;45(8):573-579.

21. Pesiridou A, Baquero G, Cristancho P, et al. A case of delayed onset of threatened premature labor in association with electroconvulsive therapy in the third trimester of pregnancy. $J$ ECT. 2010;26 (3):228-230. doi:10.1097/YCT.0b013e3181c3aef3

22. Yang HS, Seo HJ, Lee YK. Anesthetic care for electroconvulsive therapy during pregnancy -a case report. Korean J Anesthesiol. 2011;60(3):217-220. doi:10.4097/kjae.2011.60.3.217

23. Kasar M, Saatcioglu O, Kutlar T. Electroconvulsive therapy use in pregnancy. J ECT. 2007;23(3):183-184. doi:10.1097/YCT.0b013e318065b12f

24. Rose S, Dotters-Katz SK, Kuller JA. Electroconvulsive therapy in pregnancy: safety, best practices, and barriers to care. Obstet Gynecol Surv. 2020;75(3):199-203. doi:10.1097/OGX.0000000000000763

25. Balki M, Castro C, Ananthanarayan C. Status epilepticus after electroconvulsive therapy in a pregnant patient. Int $J$ Obstet Anesth. 2006;15(4):325-328. doi:10.1016/j.ijoa.2006.01.005

26. Gralnick A. Shock therapy in psychoses complicated by pregnancy; report of two cases. Am $J$ Psychiatry. 1946;102:780-782. doi:10.1176/ajp.102.6.780

27. Gilot B, Gonzalez D, Bournazeau JA, Barriere A, Van Lieferinghen P. [Case report: electroconvulsive therapy during pregnancy]. L'Encephale. 1999;25(6):590-594.

28. Livingston JC, Johnstone WM, Hadi HA. Electroconvulsive therapy in a twin pregnancy: a case report. Am J Perinatol. 1994;11 (2):116-118. doi:10.1055/s-2007-994569

29. Simon JL. Electric shock treatment in advanced pregnancy. J Nerv Ment Dis. 1948;107(6):579. doi:10.1097/00005053-194810760-00009

30. Kent EM. Shock therapy during pregnancy. Psychiatr Q. 1947;21 (1):102-106. doi:10.1007/BF01674770

31. Ferrari B. [Electroshock in treatment of some psychoses of the pregnancy]. Ann Ostet Ginecol. 1960;82:43-52.

32. Sobel DE. Fetal damage due to ECT, insulin coma, chlorpromazine, or reserpine. AMA Arch Gen Psychiatry. 1960;2:606-611. doi:10.1001/archpsyc.1960.03590120014002

33. Saltvedt S, Almstrom H, Kublickas M, Valentin L, Grunewald C. Detection of malformations in chromosomally normal fetuses by routine ultrasound at 12 or 18 weeks of gestation-a randomised controlled trial in 39,572 pregnancies. BJOG. 2006;113(6):664-674. doi:10.1111/j.1471-0528.2006.00953.x 


\section{Publish your work in this journal}

The International Journal of Women's Health is an international, peerreviewed open-access journal publishing original research, reports, editorials, reviews and commentaries on all aspects of women's healthcare including gynecology, obstetrics, and breast cancer. The

manuscript management system is completely online and includes a very quick and fair peer-review system, which is all easy to use. Visit http://www.dovepress.com/testimonials.php to read real quotes from published authors.

Submit your manuscript here: https://www.dovepress.com/international-journal-of-womens-health-journal 